\title{
Outcome of Anastomotic Urethroplasty for Bulbar Urethral Stricture Our Experience
}

\author{
Md. Shahidul Islam ${ }^{1}$, Md. Mostafiger Rahman ${ }^{2}$, Md. Fazal Naser ${ }^{3}$, Wahida Akhtar Chowdhury ${ }^{4}$ \\ Md. Abdul Baten ${ }^{5}$
}

Received: 06 - 06 - 2020

Accepted: 02 - 09 - 2020

Conflicts of interest: None

Keywords: Surgical anastomosis, Treatment outcome, Urethral stricture

\begin{abstract}
:
Objective: For evaluation of patients who underwent bulbar end-to-end anastomosis to assess surgical outcome.
\end{abstract}

\begin{abstract}
Materials and Methods: We reviewed 53 patients with an average age of 44 years who underwent bulbar end-to-end anastomosis from January 2013 to July 2018. A total of 9 patients $(16.98 \%)$ underwent urethrotomy, dilation, or multiple treatments before referral to our center. Stricture length $d^{\prime \prime} 2 \mathrm{~cm}$, free from infection and completed at least 6 months of follow up were included. Patients were evaluated post operatively by uroflowmetry at 3, 6, 12 months of follow up and yearly thereafter. Clinical outcome was considered a treatment failure when any postoperative instrumentation was needed.
\end{abstract}

Results: Mean age 44 (SD \pm 7.6 , range 33 to 54 years). Stricture etiology was blunt perineal trauma $32(60.37 \%)$, infection 12(22.64\%), idiopathic 06(11.32\%) and iatrogenic 03(05.67\%). Mean operation time was 95 minutes (range, 50 to 140 minutes) and mean excised stricture length was $1.4 \mathrm{~cm}$ (range, 0.5 to $2 \mathrm{~cm}$ ). 44 patients $(83.02 \%$ ) were symptom-free and required no further procedure. Strictures recurred in 9 patients $(16.98 \%)$ within 2 to 5 months after surgery. Of 9 recurrences, 3 patient was managed successfully by urethrotomy, whereas the remaining 6 did not respond to urethrotomy or dilation and required additional urethroplasty.

Conclusions: Excision and end-to-end anastomosis urethroplasty is an excellent procedure for short segment bulbar urethral stricture.

\section{Introduction}

Urethral stricture is an acquired permanent narrowing of the urethra impeding the flow of urine during micturition. It is one of the oldest urological diseases, and its treatment remains a challenge for urologists. ${ }^{1}$ The first known case of stricture was Indian pioneer surgeon Shusruta (1000 BC). ${ }^{2}$ Treating urethral stricture is very challenging; treatment has high failure rates and multiple postoperative complications. Treatment options for bulbar urethral strictures include dilatation, direct visual internal urethrotomy, anastomotic urethroplasty and oral mucous membrane graft urethroplasty. ${ }^{3}$ The oldest and simplest form of management is urethral dilatation, which can be performed with a number of different devices and is generally considered a palliative maneuver. In 1974, Sachse ${ }^{4}$ introduced direct vision internal urethrotomy (DVIU) to treat urethral strictures by cold-knife incision. Optical urethrotomy by either incision or ablation has been considered standard therapy for

Associate Professor, Department of Urology, Rangpur Medical College, Rangpur;

Assistant Professor, Department of Urology, Prime Medical College, Rangpur;

Associate Professor, Department of Urology, Shaheed Shahrawardy Medical College, Dhaka;

Anesthesiologist, Department of Anesthesiology, Rangpur Medical College Hospital, Rangpur;

5 Assistant Professor, Department of Urology, Shaheed Ziaur Rahman Medical College Hospital, Bogura.

Correspondence: Dr. Md. Shahidul Islam, Associate Professor, Department of Urology, Rangpur Medical College, Rangpur, E-mail: shahiduro33@gmail.com 
anterior urethral strictures and is regarded, along with dilatation, as the initial treatment of choice for most urethral strictures. In general, open urethral reconstruction is the most successful management option for urethral strictures especially stricture with complete occlusion of lumen but it requires surgical expertise, adequate operating room facilities, and has a longer recovery period..$^{5}$ Excision and end to end anastomosis (Anastomotic Urethroplasty) for bulbar urethral strictures $2 \mathrm{~cm}$ or less gives excellent long term results with reduced recurrence rate. ${ }^{6,7}$ For long segment strictures, buccal mucosa graft (BMG) augmented dorsal onlay urethroplasty is preferred. Humby was the first to describe the use of BMG for urethral reconstruction. ${ }^{5}$ In spite of the many precautions taken with each technique, the recurrence rate is very high in all types of urethroplasties. The aim of surgical reconstruction for urethral stricture is to provide an adequate caliber, compliant and stable urethra. ${ }^{8}$ There are few studies on the surgical outcomes of end-to-end anastomosis for bulbar urethral stricture in Bangladesh. We therefore performed a retrospective evaluation of patients who underwent bulbar end-to-end anastomosis to report our experience with this surgery.

\section{Materials and Methods}

We reviewed the medical documents of 53 patients who underwent excision and end-to-end anastomosis from January 2013 to July 2018 for short segment $\left(d^{\prime \prime} 2 \mathrm{~cm}\right)$ bulbar urethral strictures who completed at least 6 months of follow-up. Patients who underwent combined procedures or augmented anastomotic urethroplasty were excluded. The patient's records were reviewed with respect to etiology of stricture, previous treatment, preoperative evaluation, surgical findings, follow-up results and early and late complications. Preoperative evaluation included history, physical examination, urinalysis, urine culture, uroflowmetry, retrograde and micturating cystourethrography. Stricture length was measured intraoperatively by the excised length of urethra.

The standard surgical technique of anastomotic urethroplasty was applied while the patient was positioned in a slightly hyper-extended lithotomy position. After mobilization of the bulbar urethra, the area of fibrosis was completely excised and the healthy ends of the urethra were spatulated. Urethral mobilization was required, extending in some cases to the penoscrotal junction distally and perineal body proximally. Anastomosis was performed with interrupted 4-0 polyglactin sutures. A 16-Fr Foley urethral catheter was placed and a small drain was left under the bulbospongiosus muscle for 2 to 3 days. Patients were discharged with oral antibiotics until the catheter was removed, usually after 21 days. The urethral catheter was removed when there was no extravasation on pericatheter urethrography. The catheter was left in place an additional 1 to 2 weeks when extravasation was present.

Uroflowmetry was performed at 3, 6 months after surgery and in the first year and annually thereafter. Patients underwent retrograde urethrography or urethroscopy if they developed voiding symptoms, such as slow or splayed stream. Treatment failure was defined as the need for any postoperative intervention including urethral dilatation, Urethrotomy or urethroplasty

Table-I : Clinical data of patients

\begin{tabular}{lc}
\hline Variables & Results \\
\hline Number of patients & 53 \\
Age (years) & $44 \pm 7.6$ \\
Excised stricture length (cm) & $1.4 \pm 0.4(0.5-2)$ \\
Operation time (minutes) & $95(50-140)$ \\
Prior intervention (Dilatation, & $09(16.98 \%)$ \\
Urethrotomy) & \\
\hline
\end{tabular}

\section{Results}

We reviewed 53 patients with an average age of 44 years who underwent bulbar end-to-end anastomosis. Stricture etiology was blunt perineal trauma 32 (60.37\%), infection 12(22.64\%), idiopathic 06(11.32\%) and iatrogenic $03(05.67 \%)$. A total of 09 patients (16.98\%) underwent urethrotomy, dilation, or multiple treatments before referral to our center. Mean age $44 \pm 7.6$, range 33 to 54 years), mean excised stricture length was $1.4 \mathrm{~cm}$ (range, 0.5 to $2 \mathrm{~cm}$ ) and mean operation time was 95 minutes (range, 50 to 140 minutes). Blood transfusion (one unit) was needed in only eight patient during the operation. Overall success rate was $83.02 \%,(p=.001)$. These 44 patients were symptom-free and required no further procedure. Recurrence as treatment failure was defined as symptomatic patients requiring additional treatment; dilatation, urethrotomy or urethroplasty. Strictures recurred in 9 patients (16.98\%) within 2 to 5 months after surgery. Out of 9 recurrences, 3 patients were managed successfully by urethrotomy $(5.67 \%)$, whereas 
the remaining 6 did not respond to urethrotomy or dilation and required additional urethroplasty (11.32\%).

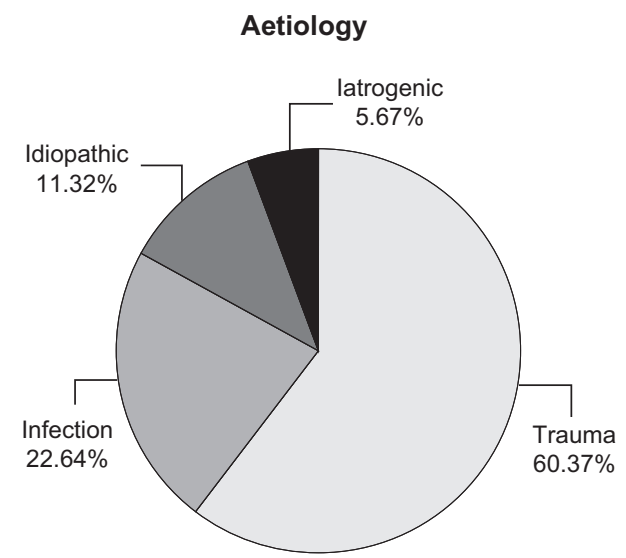

Fig.-1: Aetiology of stricture

In the success group, the mean maximum flow rate (MFR) after surgery was $20.35 \mathrm{~mL} / \mathrm{s}$. Patients aged less than 50 years $(n=41)$ showed better MFR with mean of $24.4 \mathrm{~mL} / \mathrm{s}$ (range, 18 to $42 \mathrm{~mL} / \mathrm{s}$ ) than did those aged 50 years or more $(n=12)$, who had a mean MFR of 17.23 $\mathrm{mL} / \mathrm{s}$ (range, 12 to $39 \mathrm{~mL} / \mathrm{s}$ ).

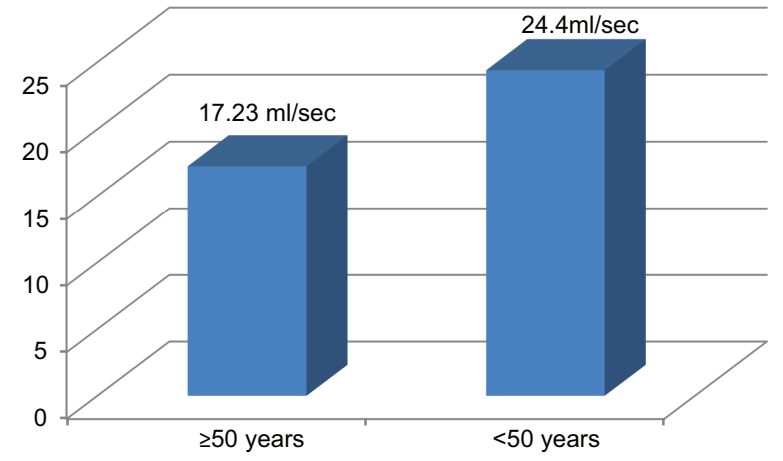

Fig.-2: Mean flow rate after surgery

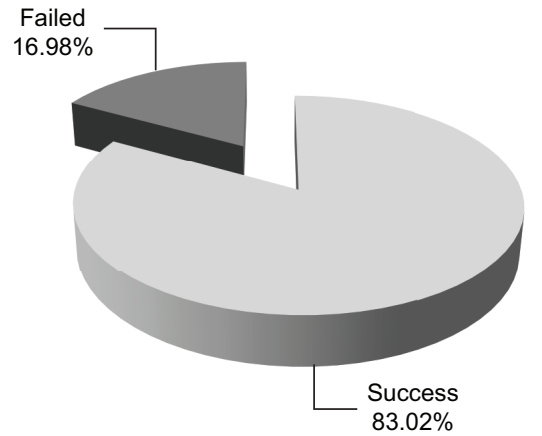

Fig.-3: Success rate.
Early complications were minor, including catheterrelated infection in four patients( $07.54 \%)$ and epididymitis in two patients $(03.77 \%)$ those were treated with antibiotics. With respect to late complications, intermittent perineal or scrotal pain bothered in eleven patients (20.75\%) and was relieved by analgesics. About seven patients (13.20\%) developed erectile dysfunction managed by medication. There are no patient complained of penile shortening or curvature.

Table-II : Complication of anastomotic urethroplasty

\begin{tabular}{ll}
\hline Type of complication & No. of patients (\%) \\
\hline Catheter-related infection & $04(07.54 \%)$ \\
Epididymitis & $02(03.77 \%)$ \\
Perineal or scrotal pain (bothered) & $11(20.75 \%)$ \\
Erectile dysfunction (Preoperative & $07(13.20 \%)$
\end{tabular}

-03, postoperative-04)

\section{Discussion}

Urethral reconstruction is the most successful management option for urethral strictures. The surgical technique should be selected mainly according to stricture length, but the stricture etiology and density of the spongiofibrosis tissue should also be taken into account. ${ }^{9}$ The aetiology of urethral stricture has evolved over the years. Geographic setting, socioeconomic factors and access to healthcare can affect stricture etiology. In developed countries, the most common etiology of urethral stricture is idiopathic $(41 \%)$ followed by iatrogenic (35\%).In comparison, trauma ( $36 \%$ ) is the most common cause in developing countries, reflecting higher rates of road traffic injuries, less developed trauma systems, inadequate roadway systems and conceivably socioeconomic factors leading to a higher prevalence of trauma-related strictures. ${ }^{10,11}$ However in our developing countries, we still see the pattern of infection and trauma; as documented in this study, where trauma and infection contributed $60.37 \%$ and $22.64 \%$ of the aetiology respectively while only 5.67 $\%$ were as a result of iatrogenic causes.

For bulbar urethral strictures of $2 \mathrm{~cm}$ or less, excision and end-to-end anastomosis remains the ideal procedure with excellent long-term results reported. ${ }^{12.13}$ A continuing role exists for urethrotomy or dilatation in the management of urethral strictures 
as first-line therapy in selected patients. In those patients with bulbar strictures who fail or are not suitable for these procedures, an anastomotic urethroplasty, and if not feasible a substitution urethroplasty using either a flap or oral mucosal graft either by a dorsal, lateral or ventral onlay approach should be considered. ${ }^{14}$

Urethral stricture disease remains a disease that affects mainly the young. In this study mean age was $44 \pm 7.6$ years and range 33 to 54 years. Ofoha et $\mathrm{al}^{3}$ demonstrated that the mean age was 38.9 years. Strictures were uncommon in those less than 20 years and above 70 years old.[15] In the management of bulbar urethral stricture, many variables, such as length, severity, and location of stricture, can influence surgical outcome. Short bulbar strictures are generally amenable to complete excision with primary anastomosis via a perineal incision, affording a high success rate of 95\%, as reported by Santucci et al.[16] Barbagli et al. ${ }^{7}$ reported 153 patients, who underwent bulbar end to end anastomosis. In his series, stricture length range $(1 \mathrm{~cm}-5 \mathrm{~cm})$ and follow up was for a period of 68 months. He reported a success rate of $90.8 \%$. Eltahawy et al. ${ }^{17}$ in a series involving 260 patients who underwent excision with primary anastomosis with mean follow up of 50.2 months, stricture length range 0.5 to $4.5 \mathrm{~cm}$ (mean 1.9), only three patients had recurrent stricture. His success rate was $98.8 \%$. Ofoha et al. ${ }^{3}$ demonstrated, twenty six patients with bulbar urethral stricture, who had excision and end to end anastomosis, had a success rate of $92.3 \%$ with a mean follow up 30.1 months. This is in keeping with the high success rate recorded by other investigators. Jun-Gyo Suh et $\mathrm{al}^{13}$ reviewed 33 patients who underwent bulbar end-to-end anastomosis; the mean excised stricture length was 1.5 $\mathrm{cm}$ (range, 0.8 to $2.3 \mathrm{~cm}$ ). Twenty-nine patients $(87.9 \%)$ were symptom-free and required no further procedure after a mean follow up 42.6 months. In this study of 53 patients with bulbar stricture end-to-end anastomosis had a success rate of $83.02 \%$ excised stricture length was $1.4 \mathrm{~cm}$ (range, 0.5 to $2 \mathrm{~cm}$ ) and mean operation time was 95 minutes (range, 50 to 140 minutes).

In general, the best stricture length manageable by excision and primary anastomosis is $2 \mathrm{~cm}$ or less $17,18,19,20$ Strictures longer than $2 \mathrm{~cm}$ can be managed successfully in selected patients with endto-end anastomosis. ${ }^{7,16,17}$ In this study, mean excised stricture length was $1.4 \mathrm{~cm}$ (range, 0.5 to $2 \mathrm{~cm}$ ). There are no cases had a stricture length more than $2.5 \mathrm{~cm}$. We consider strictures up to $2 \mathrm{~cm}$ to be suitable for primary anastomosis. To get the best results for endto-end anastomosis, complete excision of unhealthy urethra and accompanying spongiofibrosis and tension-free anastomosis are essential ${ }^{13}$. Failure to remove all abnormal urethra is thought to be the primary cause of surgical failure and stricture recurrence ${ }^{18}$ The cause of surgical failure was also assumed to be inadequate excision of the urethral stricture. ${ }^{13}$ Important steps that need to consider avoiding recurrence include maintaining the vascularity of urethra, complete excision of the fibrous tissue, and tension free anastomosis. ${ }^{20}$

For the treatment of a short segmental bulbar urethral stricture $(<2 \mathrm{~cm})$, DVIU or end-to-end urethroplasty is commonly accepted as standard therapy. ${ }^{12}$ When the stricture is limited in focal area, DVIU is recommended as the first choice of treatment. If the stricture is more than $1 \mathrm{~cm}$ in length, single DVIU followed by end-toend urethroplasty is commonly used as a cost-effective strategy. $[12,13,14]$ The literature suggests that the influence of previous treatment on surgical outcome is controversial., ${ }^{76,17.21}$ In this study, 9 out of 53 patients (16.98\%) underwent urethrotomy, dilation, or multiple treatments before anastomotic urethroplasty. Santucci et al. ${ }^{16}$ and Eltahawy et al. ${ }^{17}, 55 \%$ and $69.2 \%$ of the patients had failed attempts of urethroplasty or DVIU, respectively and surgical outcomes were equally excellent. Barbagli et al. ${ }^{7}$, the only group of patients who had a lower success rate $(78.6 \%)$ had undergone multiple treatments (dilation, DVIU, or urethroplasty), whereas the other groups (prior single or no treatment) showed similar success rates ranging from $92.1 \%$ to $100 \%$ without any statistical significance. Despite this fact, previously failed urethrotomy did not influence the long-term outcome of urethroplasty. ${ }^{21}$ However recurrent stricture were successfully managed with redo urethroplasty in six and DVIU in three patients of this study. Heyns et $\mathrm{al}^{22}$ in his review noted that dilation and internal urethrotomy are useful in a select group of patients. A second dilation or urethrotomy for early stricture recurrence (at three months) is of limited value in the short term ( 24 months) but of no value in the long term (48 months), whereas a third repeated dilation or urethrotomy is of no value.

Complications after anastomotic urethroplasty are few and self-limited. ${ }^{16,17}$ In present study, complications were intermittent perineal or scrotal pain $(20.75 \%)$, 
erectile dysfunction $13.20 \%$, catheter related infection $3.77 \%$ and epidymidis $3.77 \%$. Eltahawy et al. ${ }^{17}$ encountered position related neuropraxia, early urinary tract infection and chest related infection, scrotalgia and wound related complication. Ofoha et al. ${ }^{3}$ reported postoperative complications were mild and include superficial surgical site infection, scrotal swelling and one case of poor erection. Whereas the urologist concentrates on voiding efficiency, the patient is much more concerned with cosmetic effects and adverse effects, especially on sexual performance. ${ }^{23}$ Pelvic fracture is associated with erectile dysfunction. Many studies suggest that it is the primary injury which causes neurovascular damage that leads to ED rather than urethral surgery itself. Cavernous nerves and branches of internal pudendal artery are located near the apex of prostate and supply the corporeal bodies after entering through the urogenital diaphragm. These neurovascular bundles got damage during pelvic fracture, especially pubic symphysis diastasis. ${ }^{24,25,26,27}$ There is a close anatomical relationship between the bulbar urethra and erectile innervations. ${ }^{28}$ Recent studies have suggested that transaction of corpus spongiosum leads to less favourable outcome with regard to erectile function. ${ }^{29}$

Limitations in this study need to be considered. The main limitation of our series was its retrospective nature and small number of study patients. Potential bias and reporting errors are the main risks of any retrospective study. We assured that many of these were avoided during data collection.

\section{Conclusions}

Excision and end-to-end anastomotic urethroplasty is an excellent procedure for short bulbar urethral stricture. The most common causes of urethroplasty failure are inadequate excision of the strictured segment and surrounding fibrosis, improper case selection, and ischemia. For successful outcome bulbar urethral stricture, complete excision of scarred tissues, fixation of healthy mucosa of the two urethral ends and creation of a tension-free anastomosis are essential.

\section{References}

1. Fall B, Sow Y, Diallo Y, Sarr A, ZeondoC, Thiam A et al. Urethroplasty for male urethral strictures: Experience from a national teaching hospital in Senegal.African Journal of Urology. 2014; 20: 7681.

2. Kumar P, Khan M. The history of the catheter from Sushruta to Foley. J Urol 2009;181:386.
3. Ofoha C.G.,Shu'aibu S.I., Akpayak I.C.,Dakum N.K., Ramyil V.M.Anastomotic Urethroplasty for Short Segment Bulbar UrethralStricture; Experience at the Jos University Teaching Hospital, Jos;IOSR Journal of Dental and Medical Sciences (IOSR-JDMS) 2015;14(1):01-05

4. Lowe MA, Mason JT, Luna GK, et al. Risk factors for urethralinjuries in men with traumatic pelvic fractures. J Urol. 1988; 140:506-507.

5. Buckley JC, Heyns C, Gilling P, Carney J. SIU/ ICUD Consultation on Urethral Strictures: Dilation, internal urethrotomy, and stenting of male anterior urethral strictures. 2014;83(3 Suppl):S18-22. doi: 10.1016/j.urology.2013.08.075.

6. Santucci RA, Mario LA, McAninch JW. Anastomotic urethroplasty for bulbar urethral stricture: analysis of 168 patients. J Urol.2002;167(4): 1715-1719.

7. Barbagli G, De Angelis M, Romano G, Lazzeri M. Long-term follow up of bulbar end-to-end anastomosis: a retrospective analysisof 153 patients in a single center experience. J Urol. 2007;178(6): 2470-2473

8. Santosh KS, Devendra SP, Atul KK, Jagmohan. Transperineal bulboprostatic anastomotic repair of pelvicfracture urethral distraction defect and role of ancillary maneuver: A retrospective study in 172 patients. Urology Annals. 2010;2(2): 53-57

9. Barbagli G, Guazzoni G, Lazzeri M. One-stage bulbar urethroplasty:retrospective analysis of the results in 375 patients. Eur Urol 2008;53:828-33.

10. Stein DM, Thum DJ, Barbagli G, Kulkarni S, Sansalone S, Pardeshi A, Gonzalez CM. A geographic analysis of male urethral stricture aetiology and location. BJU Int. 2013 Oct;112(6):830-4.

11. Wessells H, Angermeier KW, Elliott S, Gonzalez CM, Kodama R, Peterson AC, Male Urethral Stricture: American Urological Association Guideline. JUrol. 2017,197(1):182-190. doi: 10.1016/j.juro.2016.07.087.

12. Rourke KF, Jordan GH. Primary urethral reconstruction: the costminimized approach to the bulbous urethral stricture. J Urol2005;173:120610.

13. Jun-Gyo Suh, Woo Suk Choi, Jae-Seung Paick, Soo Woong Kim, Surgical Outcome of Excision and 
End-to-End Anastomosis for Bulbar Urethral Stricture, Korean J Urol. 2013; 54(7): 442-447. Published online 2013 Jul 15. doi: 10.4111/ kju.2013.54.7.442

14. Mangera A, Chapple C. Management of anterior urethral stricture:an evidence-based approach. Curr Opin Urol 2010;20:453-8.

15. Palminteri E, Berdondini E, Verze P, De Nunzio C, Vitarelli A, Carmignani L. Contemporary urethral stricture characteristics in the developed world. Urology.2013; 81(1):191-196.

16. Santucci RA, Mario LA, McAninch JW. Anastomotic urethroplastyfor bulbar urethral stricture: analysis of 168 patients. JUrol 2002;167:1715-9.

17. Eltahawy EA, Virasoro R, Schlossberg SM, McCammon KA, Jordan GH. Long-term followup for excision and primary anastomosis for anterior urethral strictures.J Urol. 2007; 177(5):1803-1806.

18. Jezior JR, Schlossberg SM. Excision and primary anastomosis foranterior urethral stricture. Urol Clin North Am 2002;29:373-80.

19. Lindell O, Borkowski J, Noll F, Schreiter F. Urethral stricture repair:results in 179 patients. Scand J Urol Nephrol 1993;27:241-5.

20. Singh SK, Pawar DS, Khandelwal AK, Jagmohan. Transperinealbulboprostatic anastomotic repair of pelvic fracture urethral distractiondefect and role of ancillary maneuver: A retrospective study in172 patients. Urol Ann 2010;2:53 7.

21. Wright JL, Wessells H, Nathens AB, Hollingworth $W$. What is themost cost-effective treatment for 1 to 2-cm bulbar urethral strictures:societal approach using decision analysis. Urology 2006;67:889-93.
22. Heyns CF, Steenkamp JW, De Kock ML, Whitaker P. Treatment of male urethral strictures: is repeated dilation or internal urethrotomy useful? J Urol. 1998; 160(2):356-358.

23. Kessler TM, Fisch M, Heitz M, Olianas R, Schreiter F. Patient satisfactionwith the outcome of surgery for urethral stricture. J Urol 2002;167:2507-11.

24. Feng C, Xu YM, Yu JJ, Fei XF, Chen L. Risk factors for erectile dysfunction in patients with urethral strictures secondary to blunt trauma. J Sex Med. 2008; 5:2656-61. [PubMed] [Google Scholar]

25. Fu Q, Sun X, Tang C, Cui R, Chen L. An assessment of the efficacy and safety of sildenafil administered to patients with erectile dysfunction referred for posterior urethroplasty: A singlecenter experience. J Sex Med. 2012; 9:2827. [PubMed] [Google Scholar]

26. Lumen N, Hoebeke P, Willemsen P, De Troyer B, Pieters R, Oosterlinck W, et al. Etiology of urethral stricture disease in the 21st century. J Urol. 2009;182:983-7. [PubMed] [Google Scholar]

27. Sangkum P, Levy J, Yafi FA, Hellstrom WJ. Erectile dysfunction in urethral stricture and pelvic fracture urethral injury patients: Diagnosis, treatment, and outcomes. Andrology. 2015;3:4439. [PubMed] [Google Scholar]

28. N. Lumen, F. Poelaert, W. Oosterlinck et al., "Nontransecting Anastomotic Repair in Urethral Reconstruction: Surgical and Functional Outcomes," The Journal of Urology, vol. 196, no. 6, pp. 1679-1684, 2016.View at: Publisher Site | Google Scholar

29. S. Bugeja, D. E. Andrich, and A. R. Mundy, "Nontransecting bulbar urethroplasty," Translational Andrology and Urology, vol. 4, no. 1, pp. 41-50, 2015. View at: Google Scholar 